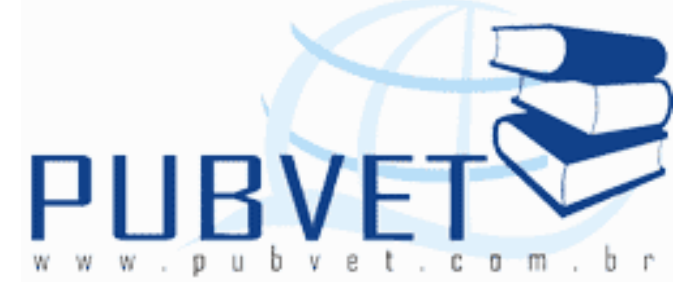

PUBVET, Publicações em Medicina Veterinária e Zootecnia.

\title{
Perfil das granjas leiteiras do Município de Caxias - MA
}

Alexandre Galdino Costa ${ }^{1}$, Mario Fernando de Assunção Sousa ${ }^{2}$, Francisco Arthu Arré2 ${ }^{2}$ Gilson Lages Fortes Portela ${ }^{2}$, Gioto Ghiarone Terto e Sousa ${ }^{3}$

${ }^{1}$ Bacharel em Zootecnia, Instituto de Ensino Superior Multiplo, IESM, Timon, Maranhão, Brasil.

${ }^{2}$ Docentes, Instituto de Ensino Superior Multiplo, IESM, Timon, Maranhão, Brasil.

${ }^{3}$ Bacharel em Zootecnia, Mestrando do Programa de Pós-Graduação em Ciência Animal, Universidade Federal do Piauí, UFPI, Teresina, Brasil.

\section{Resumo}

Este estudo teve por objetivo fazer um diagnóstico do perfil dos pequenos pecuaristas de leite do município de Caxias no estado do Maranhão. A coleta dos dados foi realizada com os produtores de leite da região baseado na indicação do Sindicato dos Produtores e Rurais e Sindicato dos Trabalhadores Rurais, os produtores foram submetidos à aplicação de questionário sócioeconômico-financeiro e técnico da produção. Os resultados permitiram conhecer as seguintes características: Instalações existentes, manejo das propriedades, vacas em produção, informações referentes a relações sociais, assistência técnica, pastagens formadas, alimentação fornecida e a infraestrutura. O rebanho da região é característico pelas seguintes raças: mestiço Holandês e girolando. A produção média é vendida "in natura" para os 
COSTA, A.G. et al. Perfil das granjas leiteiras do Município de Caxias - MA. PUBVET, Londrina, V. 6, N. 35, Ed. 222, Art. 1476, 2012.

comerciantes locais e consumidores no dia-dia sem controle da qualidade dos produtos. A alimentação é feita com forrageira, cevada, mandioca, casca da mandioca, suplementação dos animais se dá somente na época da seca, onde apresenta queda na oferta de pasto. Conclui-se que para melhorar a renda dos produtores de leite da cidade de Caxias é necessário um maior acesso à tecnologia de produção, beneficiamento e gestão da propriedade rural. Também, é necessária a criação de uma cooperativa para facilitar o escoamento da produção e fortalecer a produção leiteira da região.

Palavras-chave: alimentação, instalações, Leite.

\section{Profile of dairy farms in the municipality of Caxias}

\section{Abstract}

This study had for objective to do a diagnosis of the small cattle farmers of milk of the municipal district of Caxias profile in the state of Maranhão. The collection of the data was accomplished with the producing of milk of the area based on the indication of the Union of the Producers and Rural and Union of the Rural Workers. The producers were submitted to the application of partnereconomical-financial and technical questionnaire of the production. The results allowed to know the following characteristics: Existent facilities, handle of the properties, cows in production, information regarding social relationships, technical support, formed pastures, supplied feeding and the infrastructure. The flock of the area is characteristic for the following races: Dutch mestizo and girolando. The medium production is sold "in natura" for the local and consuming merchants in the day-day without control of the quality of the products. The feeding is made with, forage barley, cassava, peel of the cassava, supplementation of the animals if he/she only gives at that time of the drought, where it presents fall in the pasture offer. It is ended that is necessary a larger access to the production technology, improvement and administration of the rural property to improve the income of the producing of 
COSTA, A.G. et al. Perfil das granjas leiteiras do Município de Caxias - MA. PUBVET, Londrina, V. 6, N. 35, Ed. 222, Art. 1476, 2012.

milk of the city of Caxias. Also, it is necessary the creation of a cooperative to facilitate the drainage of the production and to strengthen the production milk pan of the area.

Keywords: Feeding, facilities, Milk

\section{Introdução}

A produção mundial de leite, em 2008, chegou a mais de 578 bilhões de litros, segundo a Organização das Nações Unidas para Agricultura e Alimentação (FAO). Os Estados Unidos lideram o ranking de países produtores com mais de 86 bilhões de litros produzidos, seguindo-se a Índia com uma produção de 44 bilhões. O Brasil aparece como o sexto maior produtor, com mais de 27 bilhões de litros (BOLETIM DO AGRONEGOCIO, 2010).

O Brasil vem apresentando um constante crescimento na produção de leite. Só em 2008, a produção nacional apresentou um crescimento de 5,5\%, quando comparada com 2007. A participação da Região Nordeste em relação à produção nacional vem ganhando força na última década, tendo sido a terceira região que mais cresceu em participação neste período - cerca de 69\%. Atualmente o Nordeste brasileiro é responsável por $12 \%$ de todo o leite produzido no país litros (BOLETIM DO AGRONEGOCIO, 2010).

O Brasil apresenta alta produção de leite, mas a sua produtividade é baixa quando comparada a outros países. São várias as opções de raças e cruzamentos para a bovinocultura leiteira, sendo as mais exploradas: raças europeias especializadas como a Holandesa, a Pardo - Suíça e a Jersey; raças zebuínas leiteiras, como a Gir e a Guzerá; vacas mestiças, resultantes do cruzamento de raças europeias com raças zebuínas, em vários graus de sangue (SARCINELLI et al., 2007).

O Brasil apresenta condições climáticas, socioeconômicas e culturais diversas em suas regiões, que demandam soluções distintas e construções zootécnicas adequadas a todos os sistemas de produção. Construções zootécnicas apropriadas, que garantam condições necessárias de conforto, 
COSTA, A.G. et al. Perfil das granjas leiteiras do Município de Caxias - MA. PUBVET, Londrina, V. 6, N. 35, Ed. 222, Art. 1476, 2012.

contribuem com o aumento da produtividade e permitem ao animal abrigado condições para expressar o seu potencial genético (MILANI; SOUZA, 2010).

O leite é produzido em quase todos os países do mundo e apresenta grande importância para a alimentação humana devido ao seu alto valor nutritivo e geração de renda a milhares de produtores.

Porém de acordo com Crevelin (2007) tem sido realizada a busca por alternativas que possam contribuir para a melhoria de algumas variáveis que afetam a competitividade da produção leiteira na atividade desenvolvida por agricultores familiares. Produzindo leite de boa qualidade em menos custo. $O$ trabalho teve como objetivo construir um perfil socioeconômico das granjas leiteiras localizadas no município de Caxias.

\section{Material e métodos}

O município de Caxias tem uma população de 155.129 habitantes, segundo o Censo de 2010 do IBGE. "A "cidade está situada no leste maranhense, com Latitude 04051'34" S e Longitude 43021'20" O, numa altitude de $141 \mathrm{~m}$. Está localizado na Mesorregião Leste Maranhense, na Microrregião de Caxias, com uma área territorial de $5.209 \mathrm{Km} 2$ e uma população de 141.686 habitantes. Os trabalhos foram iniciados em julho de 2011.

Os produtores entrevistados foram indicados pelo Sindicato dos Produtores Rurais e pelo Sindicato dos Trabalhadores Rurais, englobando 19 famílias atendidas. A criação do questionário levou em consideração a caracterização do produtor, a caracterização de sua propriedade e rebanho, práticas agrícolas e de manejo, além-informações referentes a relações sociais, assistência técnica, perspectivas da atividade leiteira, e outras informações complementares.

Posteriormente os questionários foram aplicados individualmente através de visitas às propriedades, onde 0 aplicador obtinha as informações necessárias por meio das perguntas. Com base nestas entrevistas foram 
COSTA, A.G. et al. Perfil das granjas leiteiras do Município de Caxias - MA. PUBVET, Londrina, V. 6, N. 35, Ed. 222, Art. 1476, 2012.

obtidas as informações que depois de tabuladas foram posteriormente analisadas.

\section{Resultados e discussão}

Dos pequenos produtores de gado de leite entrevistados no município de Caxias, 78 \% são casados e $22, \%$ são solteiros, isso mostra um maior percentual de produtores com união estável, fortalecendo trabalho na propriedade visando o menos custo na mão de obra, sendo de caráter familiar (Figura 01).

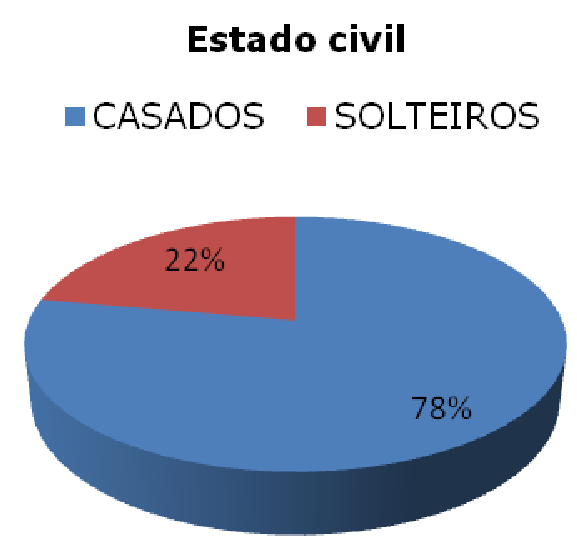

Figura 01. Distribuição dos produtores quanto ao estado civil em caxias -MA em 2011.

De acordo com as propriedades entrevistadas todos são proprietários, ou seja, em relação condição de terra $100 \%$ trabalham em terras próprias (Figura 02).

Com relação ao nível educação $27 \%$ são alfabetizados. $25 \%$ são analfabetos, com $24 \%$ tem ensino fundamental, vale ressaltar que $17 \%$ têm ensino médio e apenas 7 $\%$ tem ensino superior. Quanto à situação que ocorre no meio rural, pela dificuldade em conciliar os estudos com o trabalho na propriedade, quando há um trabalho mais intenso que pode significar uma melhoria na renda familiar. O Nível de escolaridade é importante para os produtores entenderem as modificações propostos pelas novas tecnologias (figura 03). 
COSTA, A.G. et al. Perfil das granjas leiteiras do Município de Caxias - MA. PUBVET, Londrina, V. 6, N. 35, Ed. 222, Art. 1476, 2012.

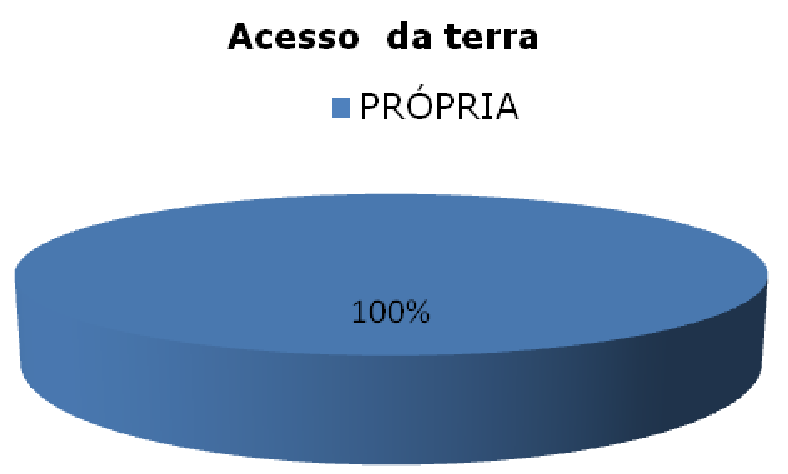

Figura 02. Participação dos produtores rurais quanto ao acesso a terra em Caxias - MA em 2011.

\title{
Nivel de escolaridade
}

\author{
-ALFABETIZADO \\ ANALFABETO \\ - ENSINO MEDIO \\ ENSINO FUNDAMENTAL
}

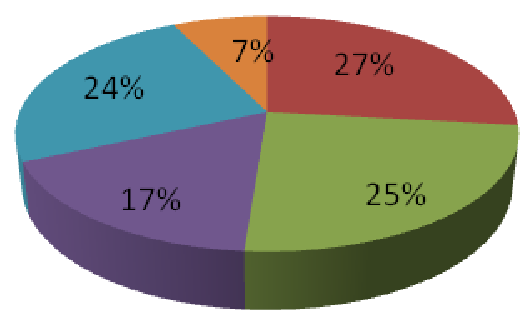

Figura 03. Participação dos produtores quanto ao nível de escolaridade.

Com relação à idade dos produtores de 0 a 10 anos tem uma percentagem de $14,5 \%$, de 10 a 20 anos com $14,5 \% \%$, com $31,25 \%$ de 20 a 40 anos, de 40 a 60 anos com 33,5\% e maior que 60 anos 6,25\%. A informação sobre a idade dos produtores é de extrema importância para caracterizar o perfil da propriedade. Produtores com diferentes faixas etárias exigem abordagens diferenciadas com uma atenção melhor, caso tenha capacitações (Figura 04). 
COSTA, A.G. et al. Perfil das granjas leiteiras do Município de Caxias - MA. PUBVET, Londrina, V. 6, N. 35, Ed. 222, Art. 1476, 2012.

\section{Faixa etaria de idade}
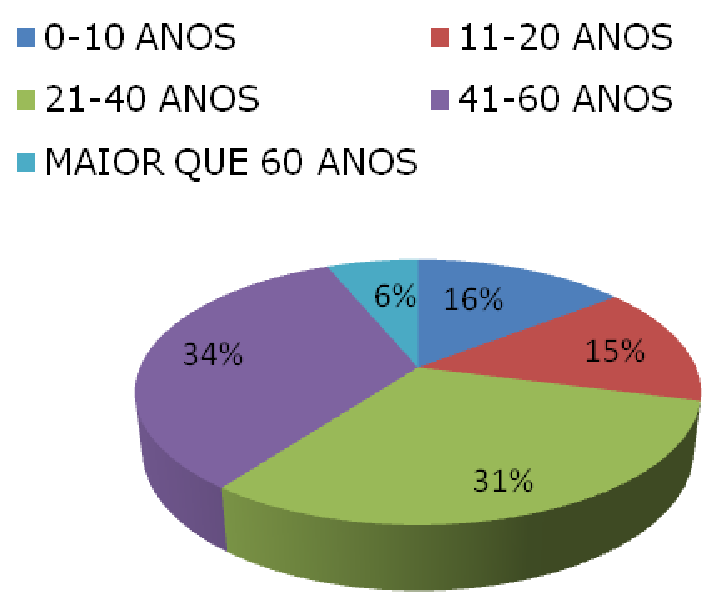

Figura 04. Distribuição de Faixa etária de idade dos produtores.

Com relação à moradia, $83 \%$ das casas são de alvenaria simples e $17 \%$ são de taipa demonstrando as dificuldades sofridas por esses produtores. Normalmente os produtores refletem em bens duráveis como, carro moto, animais, residências que possa Ihe dar conforto (Figura 05).

\section{Condições de moradia}

$\square B O A=$ RUIM

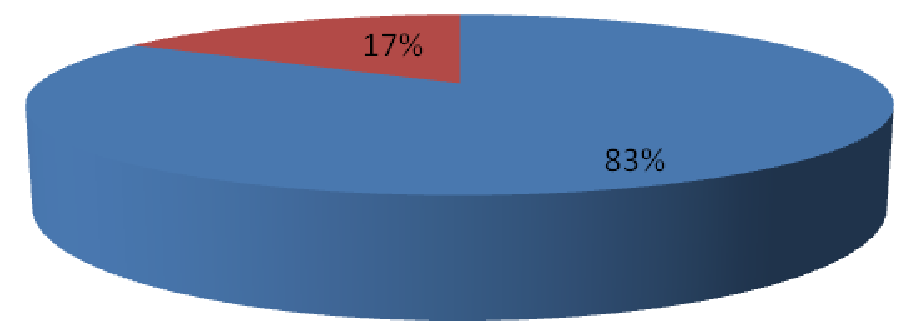

Figura 05. Tipo de moradia dos produtores rurais em Caxias - MA.

Com relação a produção apenas $11 \%$ é transformada em queijo e o resto é comercializado como leite in natura. A falta de capacitação é um dos 
COSTA, A.G. et al. Perfil das granjas leiteiras do Município de Caxias - MA. PUBVET, Londrina, V. 6, N. 35, Ed. 222, Art. 1476, 2012.

entraves para beneficiar a produção. Castro et al. (2010)ainda afirma em seu trabalho que alguns produtores fabricam o queijo para seu próprio consumo(Figura 06).

Identificação do produto

- LEITE \& QUEIJO

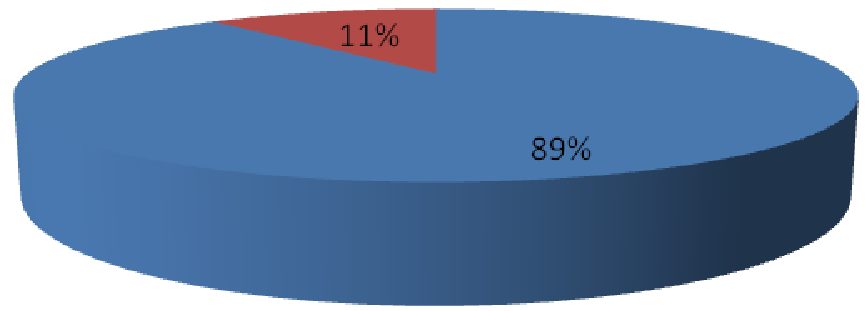

Figura 06. Participação dos produtores na produção de queijos e leite.

$\mathrm{Na}$ atualidade17 \% usam ordenha mecanizada, $83 \%$ retiram o leite manual. Afirma Sá et al. (2005) que os pequenos produtores continuará produzindo leite de forma artesanal, algumas vezes sem condições adequadas de higiene. Após a ordenha o leite segue em latões apropriados para o consumidor (Figura 07).

\section{Ordenha mecanizada}

$\because \mathrm{SIM} \sim \mathrm{NA \tilde {O }}$

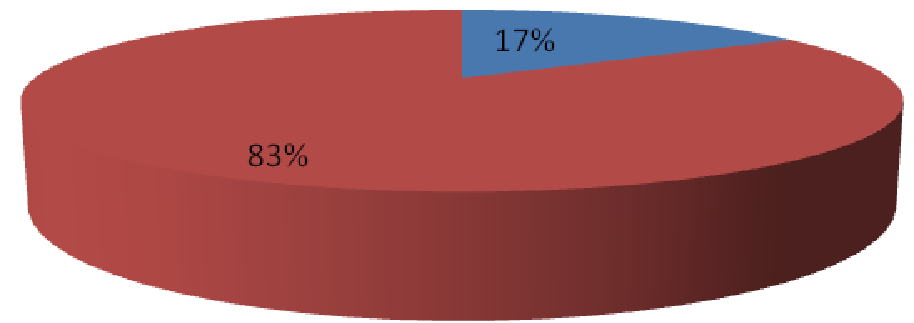

Figura 07. Distribuição dos produtores que trabalham com ordenha mecanizada. 
COSTA, A.G. et al. Perfil das granjas leiteiras do Município de Caxias - MA. PUBVET, Londrina, V. 6, N. 35, Ed. 222, Art. 1476, 2012.

Com relação à ordenha, são realizadas em dois turnos, sendo que $65 \%$ realizam pela manha e $35 \%$ no turno da tarde (Figura 08).

\section{Horários da ordenha}

n 04 hrs $\square 14$ hrs

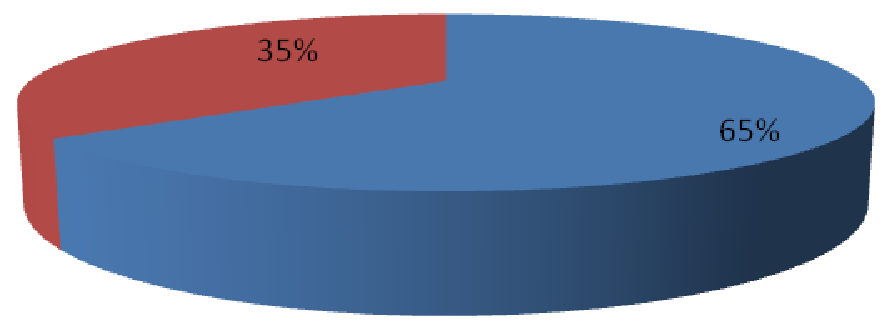

Figura 08. Distribuição dos produtores quanto ao horário da ordenha.

Com relação ao teste da caneca telada 72 \% fazem o teste da caneca telada e $28 \%$ nunca fizeram o teste por falta de conhecimento. Segundo Bento Junior (2006) em um assentamento em imperatriz as praticas higiênicas ficam a desejar com um índice extremamente baixo ao teste de mastite e no que se refere ao uso do coador $62,50 \%$ (Figura 09 ).

\section{Teste da caneca de fundo preto}

$$
\text { - SIM }=\text { NÃO }
$$

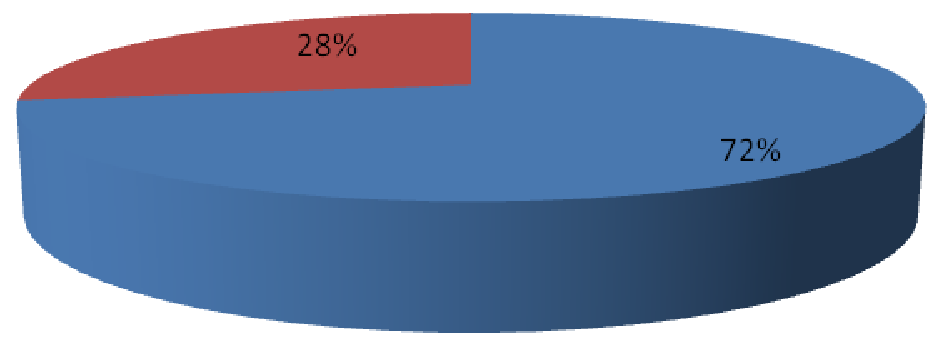

Figura 09. Participação dos Produtores quanto ao Teste da caneca telada. 
COSTA, A.G. et al. Perfil das granjas leiteiras do Município de Caxias - MA. PUBVET, Londrina, V. 6, N. 35, Ed. 222, Art. 1476, 2012.

Dos entrevistados 95 \% não fazem a resfriação do leite, não há estrutura de resfriamento, uma vez que todo o leite é retirado logo após a ordenha e comercializado no mesmo dia. Paula (2008) em pesquisa realizada na região de Colinas Maranhão não há estrutura de resfriamento do leite, uma vez que todo o leite é retirado logo após a ordenha e comercializado no mesmo dia. A existência de energia elétrica instalada possibilitaria tal procedimento.

\section{Resfriamento do leite}

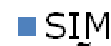

- NÃO

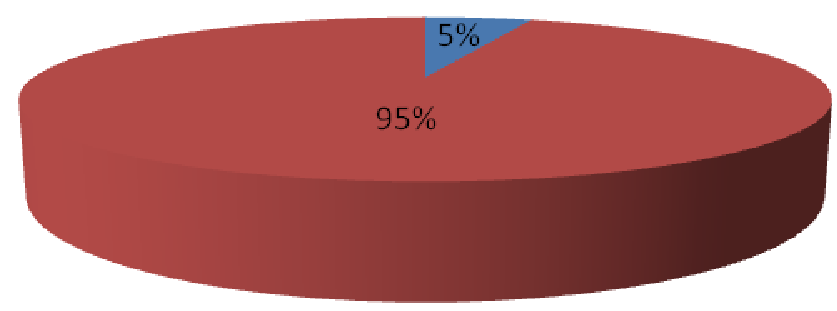

Figura 10. Participação dos produtores quanto ao resfriação do leite.

As propriedades visitadas produzem em média 0 a 10 Litros de leite por vaca que equivale $83 \%$ das propriedades visitadas e de $10-20$ Litros só $17 \%$. Paula (2008) com relação à produção de leite em seu trabalho na cidade de Açailândia, maior produtor de leite do Estado, é uma exceção positivamente, pois está muito acima do índice nacional. Já Caxias, um município de grande expressão estadual nos diversos setores de sua vida política, cultural, econômica e social, apresenta um consumo per capita de leite baixo (Figura 11). 
COSTA, A.G. et al. Perfil das granjas leiteiras do Município de Caxias - MA. PUBVET, Londrina, V. 6, N. 35, Ed. 222, Art. 1476, 2012.

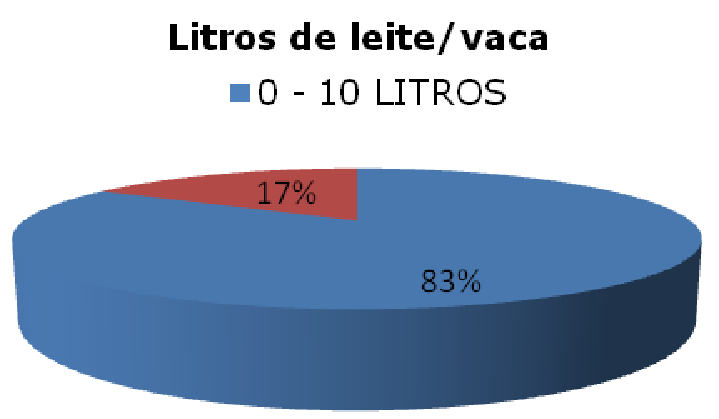

Figura 11. Distribuição dos produtores quanto aos Litros de leite /vaca.

Com relação os carrapaticidas $39 \%$ utilizam no seu rebanho botox, $33 \%$ usam o barragem e $28 \%$ o IVOMEC (Figura 12 ).

\section{Carrapaticidas}

- BUTOX $\quad$ BARRAGEM

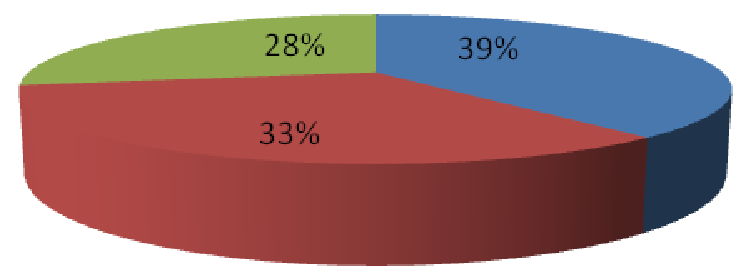

Figura 12. Distribuição de carrapaticidas.

Das fazendas produtoras de leite, em Caxias, conforme foi constatado na Pesquisa de Campo, 89 \% tem instalações à maioria boas, são construídos com material muito bom, apresentando ótimas instalações. Mas as condições de higiene precisam ser melhoradas em algumas delas. As instalações são básicas, com exceção de algumas que são precárias com $11 \%$, mas em condições possíveis de melhoria. Paula (2008) em seu trabalho em colinas diz que as maiorias dos produtores não têm estrutura de produção aceitável. Dizem, na entrevista, que têm curral e brete, mas, na verdade, é apenas uma 
COSTA, A.G. et al. Perfil das granjas leiteiras do Município de Caxias - MA. PUBVET, Londrina, V. 6, N. 35, Ed. 222, Art. 1476, 2012.

área cercada e coberta - às vezes com palha - onde fazem a ordenha (Figura 13).

\section{Condições das instalações}

$\square \mathrm{BOA}$

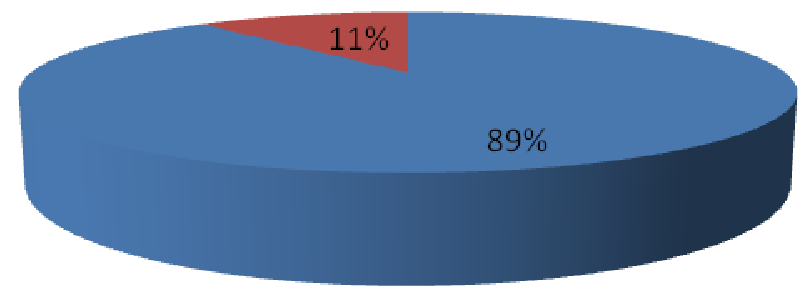

Figura 13. Distribuição das Condições das instalações dos entrevistados.

Dos produtores entrevistados $100 \%$ possuem energia elétrica. Água e ótimas vias de acesso, o que facilita a produção e a comercialização. Das propriedades entrevistadas $83 \%$ não recebem assistência técnica e $17 \%$ recebem assistência com oscilação. Afirma Sá et al. (2005) em seu trabalho realizado no semi árido sergipano que Cerca de $67 \%$ dos entrevistados relataram não receber nenhum tipo de assistência técnica (Figura15). Os outros 32\% recebem auxílio técnico do DEAGRO (Departamento de Assistência Agropecuária do Estado de Sergipe). 
COSTA, A.G. et al. Perfil das granjas leiteiras do Município de Caxias - MA. PUBVET, Londrina, V. 6, N. 35, Ed. 222, Art. 1476, 2012.

\section{Assistência técnica}

$\backsim \mathrm{SIM} \backsim \mathrm{NA \tilde {O }}$

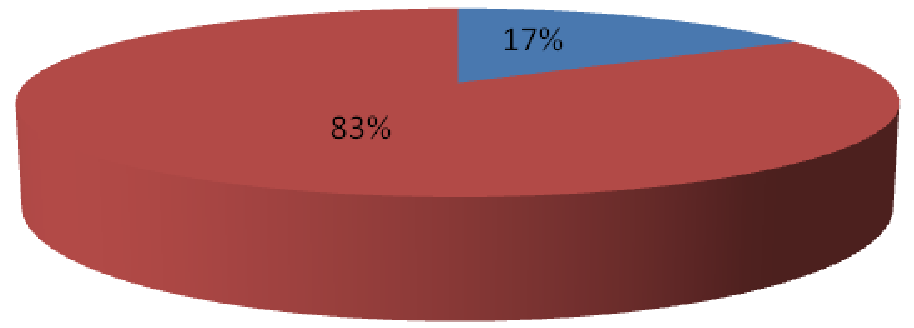

Figura 14. Distribuição dos produtores quanto a Assistência técnica.

Com relação às raças utilizadas 39\% dos produtores utilizam animais mestiços de holandês, $28 \%$ com mestiços de girolanda, 22\% gado holandês e $11 \%$ com animais Gir, conforme gráfico 15.

\section{Raças}

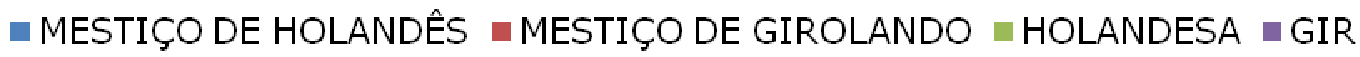

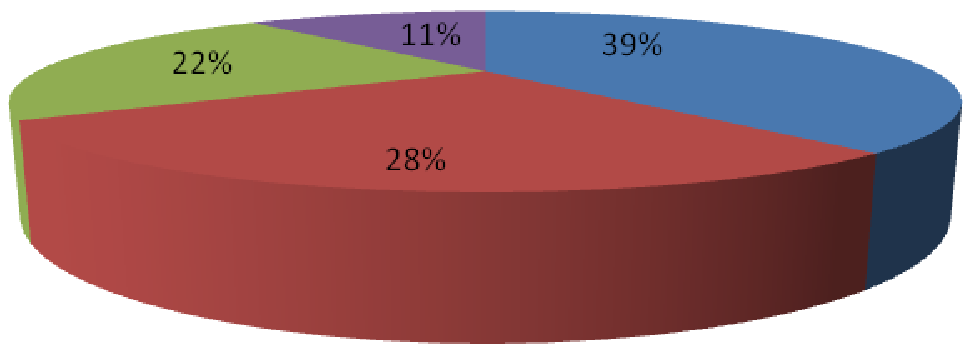

Figura 15. Participação dos produtores rurais quanto às raças em Caxias - MA.

Dos produtores entrevistados com $28 \%$ tem de 0 a 10 animais. $28 \%$ na faixa de 11 a 20 animais, e $28 \%$ com 21 a 40 animais. Com $28 \%$ com cerca 
COSTA, A.G. et al. Perfil das granjas leiteiras do Município de Caxias - MA. PUBVET, Londrina, V. 6, N. 35, Ed. 222, Art. 1476, 2012.

de 41 a 60 animais e com um numero maiores de animais 5,5\% com mais de 60 animais (Figura 16).

\section{Quantidade de animais}

$\begin{array}{ll}\square-10 \text { ANIMAIS } & \square 11-20 \text { ANIMAIS } \square 21-40 \text { ANIMAIS } \\ & \text { 41-60 ANIMAIS } \quad \square \text { MAIS DE } 60 \text { ANIMAIS }\end{array}$

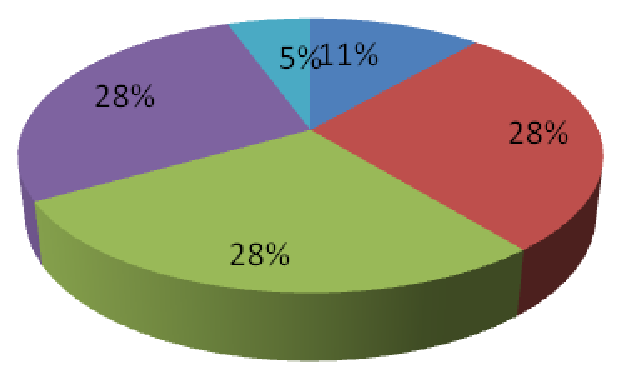

Figura 16. Participação dos produtores quanto a Quantidade dos animais.

Com relação os insumos usados na produção $29 \%$ usam plantas forrageiras e cevada, $27 \%$ utilizam mandioca, $12 \%$ utilizam farelo de soja e 3 \% casca da mandioca, e todos dos produtores utilizam sal mineral. Paula (2008) confirma em pesquisa na cidade de Colinas que na alimentação suplementar na verdade apenas o fornecimento de cuim de arroz com mandioca, é fornecido em recipientes inadequados, sem higiene, como cochos quebrados de madeira e de pneus. Instalações hidráulicas para a limpeza, quando existem, apenas uma torneira com mangueira (Figura 17). 
COSTA, A.G. et al. Perfil das granjas leiteiras do Município de Caxias - MA. PUBVET, Londrina, V. 6, N. 35, Ed. 222, Art. 1476, 2012.

\section{Insumos usados na produção}

$\begin{array}{ll}\square \text { FORRAGEIRAS } & \text { MANDIOCA } \\ \square \text { CEVADA } & \text { FARELODE SOJA } \\ \square \text { CASCA DA MANDIOCA }\end{array}$

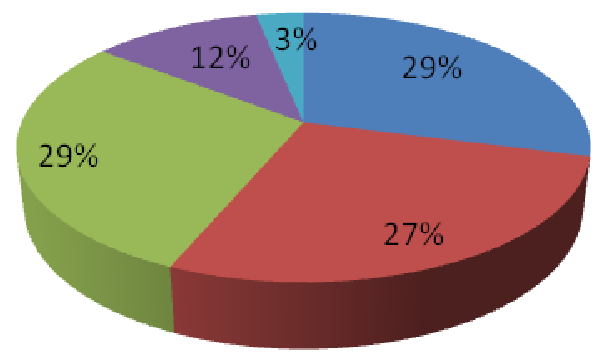

Figura 17. Insumos usados na produção dos entrevistados.

Todos os criadores entrevistados vacinam os animais, sendo as principais vacinas citadas, aquelas utilizadas para a prevenção da febre aftosa, manqueira e raiva. Das propriedades entrevistadas cerca de $44 \%$ do leite é transportado em saco plástico de $1 \mathrm{~kg} .56$ \% são em tambor de plástico de 50 litros. Paula (2008) afirma que leite produzido é recolhido em baldes de plástico, em dimensões diversas, conforme o volume da produção, com venda imediata direta aos consumidores (50\%), sem passar por nenhum tipo de exame (Figura 18). 
COSTA, A.G. et al. Perfil das granjas leiteiras do Município de Caxias - MA. PUBVET, Londrina, V. 6, N. 35, Ed. 222, Art. 1476, 2012.

\section{Transporte do leite}

-SACO

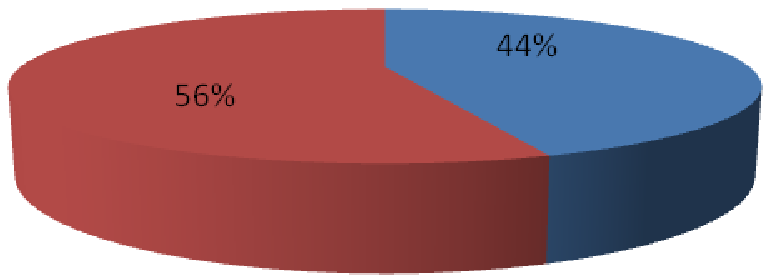

Figura 18. Distribuição dos produtores quanto aoTranspote do leite.

Dos meios de transportes $55 \%$ dos produtores têm carros que facilitam a entrega do leite produzido e que contribui para dar assistência à propriedade, $28 \%$ têm moto e $16 \%$ tem bicicleta, temos dificuldade de fazer a entrega do leite (Figura 19).

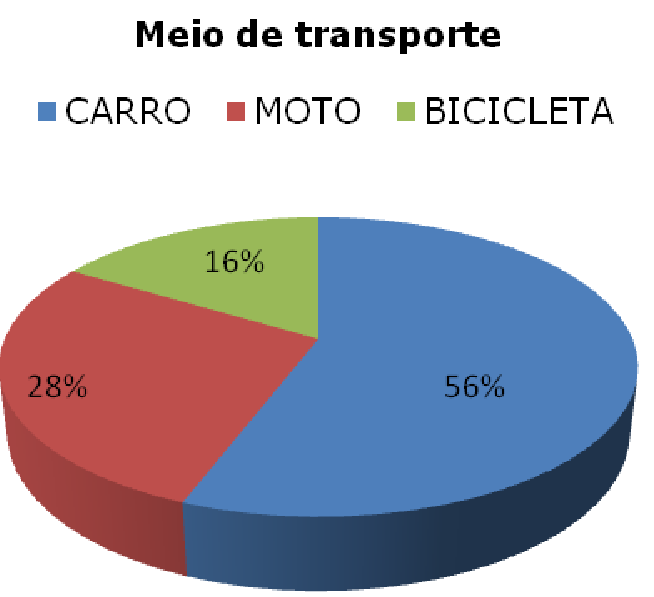

Figura 19. Distribuição dos Meios de transportes dos produtores.

Do total do leite comercializado $83 \%$ é vendido diretamente ao consumidor ao preço ao preço de 1,00 a 1,50 , os outros $17 \%$ é comercializado a um preço, maior que 1,50. Confirmando Paula (2008). Na cidade de colinas maranhão o leite vendido a intermediários tem o preço de $R \$ 1,00$ a $R \$ 1,30$, enquanto que ao consumidor direto é vendido por $\mathrm{R} \$ 1,50$ (Figura 20). 
COSTA, A.G. et al. Perfil das granjas leiteiras do Município de Caxias - MA. PUBVET, Londrina, V. 6, N. 35, Ed. 222, Art. 1476, 2012.

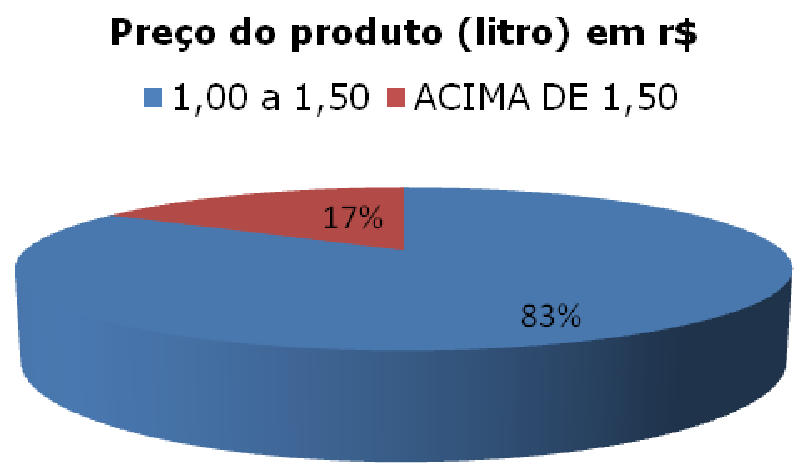

Figura 20. Distribuição dos produtores com relação ao Preço do produto.

Segundo os produtores $75 \%$ da produção vendem para o comércio. Outros $20 \%$ vendem o leite para população de porta em porta e $4 \%$ vendem para o laticínio. Confirma Veloso et al. (2005) que mais chama a atenção o fato de $94,9 \%$ dos produtores de leite da bacia leiteira de Teresina comercializam o leite In Natura (Figura 21).

\section{Para quem vende sua produção}

-COMERCIO $\because$ COMUNIDADE $\square$ LATICÍNIO

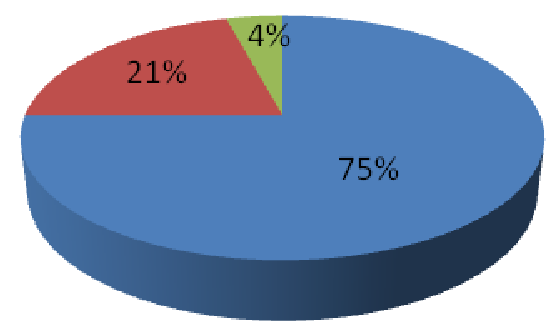

Figura 21. Para quem vende sua produção.

Das propriedades entrevistadas $61 \%$ têm forrageiras, enquanto $8 \%$ tem ensilhadeira. Com 19 \% tem carroça para dar suporte na alimentação dos 
COSTA, A.G. et al. Perfil das granjas leiteiras do Município de Caxias - MA. PUBVET, Londrina, V. 6, N. 35, Ed. 222, Art. 1476, 2012.

animais e $8 \%$ tem caminhão para facilitar na assistência no dia- dia na propriedade e apenas $3 \%$ tem trator (Figura 22 ).

\section{Equipamentos da propriedade}

-FORRAGEIRA $=$ CARROÇA $=$ ENSILADEIRA $\approx$ CAMINHÃO $=$ TRATOR

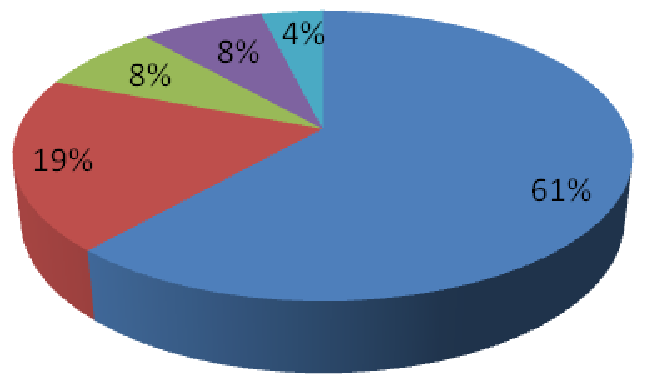

Figura 22. Distribuição dos produtores rurais quanto aos Equipamentos usados na propriedade.

No que se refere à renda mensal 74\%. Dos produtores tem renda de 1 a 4 salários mínimo, $16 \%$ tem renda de 4 a 8 e apenas $10 \%$ tem renda superior a 8 salários mínimos, como mostra (Figura 23).
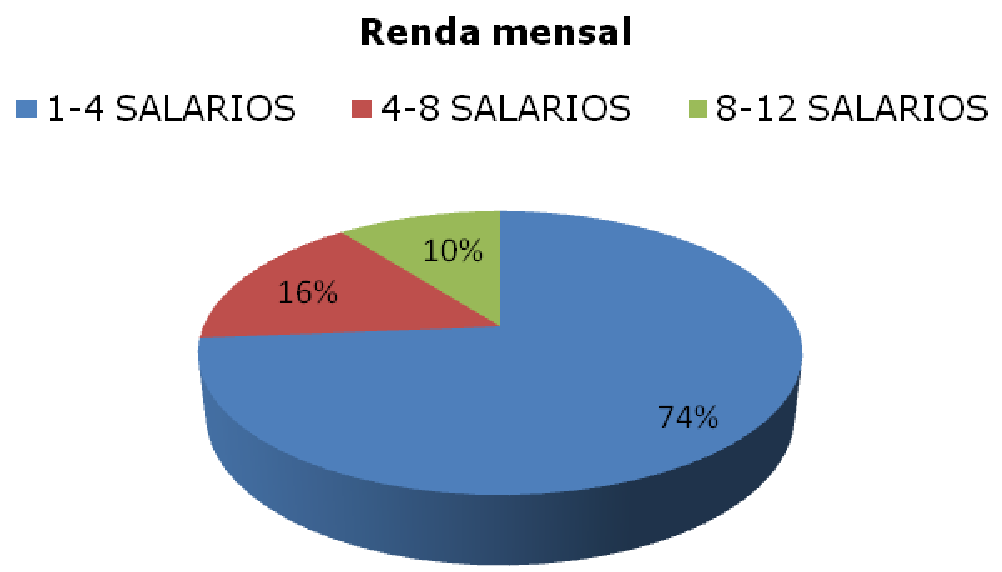

Figura 23. Distribuição dos produtores quanto a renda da produção.

Com relação finalidade da produção $55 \%$ tem atividade para alto se sustentar e $44 \%$ para ter uma renda extra, vale ressaltar que estes dados 
COSTA, A.G. et al. Perfil das granjas leiteiras do Município de Caxias - MA. PUBVET, Londrina, V. 6, N. 35, Ed. 222, Art. 1476, 2012.

demonstram que essa atividade de produção leiteira é atividade complementar para abastecimentos da família, ou seja, para o complemento da renda da família (Figura 24).

\section{Finalidade da produção}

- ALTO SE SUSTENTAR $\quad$ RENDA EXTRA

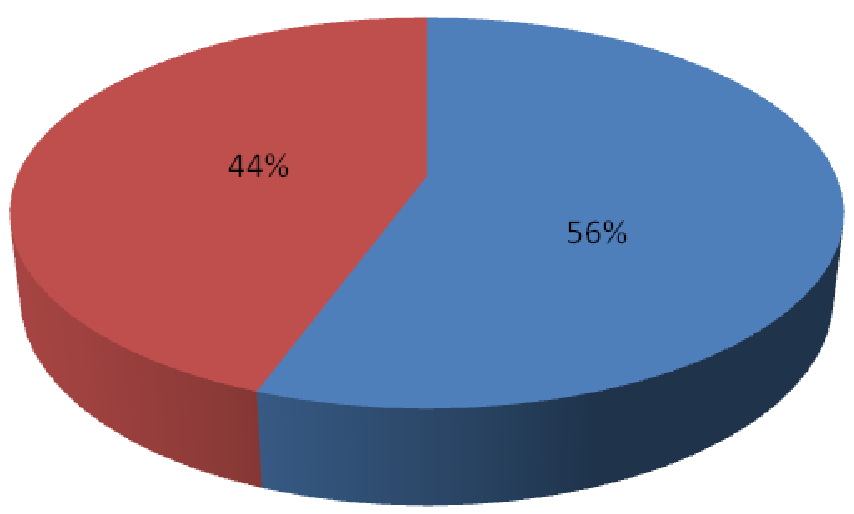

Figura 24. Com relação à Finalidade da produção dos produtores em Caxias.

\section{Conclusão}

Com os dados obtidos no trabalho, a bovinocultura leiteira do município de Caxias tem uma importante contribuição para o desenvolvimento da agricultura familiar. Existem alguns gargalhos que não levam ao crescimento na produção, insumos com custo elevado, falta de assistência técnica, capacitação para os produtores e dificuldade acesso ao crédito. Porém, existe a necessidade de uma maior tecnificação da produção. Nesse contexto, a organização dos produtores é condição importante para desenvolvimento da atividade com a formação de uma cooperativa para redução dos custos de produção e aumento da lucratividade. 


\section{Referências bibliográficas}

BENTO JUNIOR, F. de A. et al. Caracterização da bovinocultura de leite no assentamento itacira I,município de imperatriz -maranhão. ZOOTEC 2006 - 22 a 26 de maio de 2006 - Centro de Convenções de Pernambuco.

BOLETIM SETORIAL DO AGRONEGÓCIO. Bovinocultura leiteira Recife, agosto de 2010.

CANI, P. C.; FRANGILO, R. F. Como produzir leite de qualidade. ACPGLES - Associação de Criadores e Produtores de Gado de Leite do Espírito Santo. Vitoria - ES 2008.

CASTRO, K. N. de C. et al. Característica Da Pecuária Leiteira no Assentamento Fazenda Nova Da Lagoa Grande Em Dourados, MS. Empresa Brasileira De Pesquisa Agropecuária, Embrapa Agropecuária Oeste, Ministério Da Agricultura, Dezembro De 2010.

CREVELIN, S. A.; SCALCO, R. A. Projeto "agricultura familiar gado de leite": melhorias ocorridas em uma propriedade familiar no município de tupã. UNESP/CEPEAGRO, TUPÃ, SP, BRASIL. XIv congresso da sociedade brasileira de economia e administração e sociologia rural Londrina - PR, 2007.

CHIODI, M. S. et al. Grupo de estudo em bovinocultura leiteira - gebo/ ano 2010.

GAIOSKI, L. J. et al. Levantamento estatístico de produtores participantes do projeto "transferências de tecnologia de beneficiamento e industrialização de leite em estabelecimentos familiares com produção de leite". Salão de extensão e cultura 2008.

MILANI, A. P.; SOUZA, F. A. de. Granjas leiteiras na região de Ribeirão Preto. Engenharia Agrícola, Jaboticabal, v.30, n.4, p.742-752, jul/ago.2010.

PAULA, V. C. de. Potencial Leiteiro Do Município De Colinas - Ma. Serviço De Apoio Às Micro E Pequenas Empresas Do Piauí SEBRAE/MA, abril 2008.

PORTELA, J. N. et al. Análise econômica de sistemas de produção com bovinocultura de leite da depressão central do rio grande do sul. Ciência Rural, Santa Maria, v.32, n.5, p.855-861, 2002.

SARCINELLI, M. F. et al. Produção de bovinos- tipo leite. Universidade Federal do Espírito Santo - UFES (Boletim Técnico), 2007.

SÁ, J. L. de. et al. Produção animal de base familiar no semiárido sergipano1, 2005.

VELOSO, R. S. et al. Diagnóstico Socioeconômico Das Bacias Leiteiras De Parnaíba-Pi e Teresina-Pi. Serviço De Apoio Às Micro E Pequenas Empresas Do Piauí SEBRAE/PI, 2005. 